\title{
Lift the veil of the block samples from the Warcq chariot burial with 3D digital technologies
}

\author{
Théophane Nicolas \\ Laboratoire CNRS Trajectoires \\ (UMR 8215) \\ Inrap \\ Rennes, France \\ Emilie Millet
Inrap
Reims, France
}

\author{
Ronan Gaugne \\ Univ Rennes, Inria, CNRS, IRISA \\ Rennes, France \\ Email: ronan.gaugne@irisa.fr
}

Renaud Bernadet

Independent curator

Paris, France

\author{
Cédric Tavernier \\ Image ET \\ Mordelles, France
}

\author{
Valérie Gouranton \\ Univ Rennes, INSA Rennes, Inria, \\ CNRS, IRISA \\ Rennes, France
}

\begin{abstract}
Cultural Heritage (CH) professionals such as archaeologists and conservators regularly experience the problem of working on concealed artifacts and face the potential destruction of source material without real understanding of the internal structure or state of decay or modification of the initial context by the micro-excavation process. Medical images-based digitization, such as MRI or CT scan, are increasingly used in $\mathrm{CH}$ as they provide information on the internal structure of archaeological material. Likewise, additive technologies are used more and more in the Cultural Heritage process, for example, in order to reproduce, complete, study or exhibit artifacts. 3D copies are based on digitization techniques such as laser scan or photogrammetry. In this case, the 3d copy remains limited to the external surface of objects. Different previous works illustrated the interest of combining 3D printing and Computed Tomography (CT) scans in order to extract concealed artifacts from larger archaeological material. The method was based on 3D segmentation techniques within volume data obtained by $C T$ scans to isolate nested objects. This approach was useful to perform a digital extraction, but in some case it is also interesting to observe the internal spatial organization of an intricate object in order to understand its production process. We propose a method for the representation of a complex internal structure based on a combination of $\mathrm{CT}$ scan and emerging 3D printing techniques mixing colored and transparent parts of an aggregate of objects, with very small pieces, from an exceptional aristocratic Gallic grave in the context of a preventive archaeological investigation.
\end{abstract}

\section{Keywords-archaeology, CT scan, 3D printing}

\section{INTRODUCTION}

Cultural Heritage professionals such as archaeologists and conservators regularly experience the problem of working on concealed artifacts and face the potential destruction of source material without real understanding of the internal structure or state of decay. For example, artifacts may be encased in corroded materials or a block of ash, or integrated with, and inseparable from, larger assemblies, such as manufactured objects composed of several pieces. Archaeological artifacts and the sediments that contain them constitute the sometimes tenuous evidence that requires analysis, preservation and showcasing. Different methods of digital analysis that provide non-destructive solutions to preserve, analyze and showcase archaeological heritage have been developed over recent years. However, these techniques are often restricted to the visible surface of the objects,

This work was partially funded by the ANR-16-FRQSC-0004 INTROSPECT project and the CNRS Interdisciplinary Imag'in Project IRMA. monuments or sites.

The techniques used in medical imaging are more and more frequently used in archaeology as they give nondestructive access to the artifacts' internal and often fragile structure. This use is mostly limited to a simple visualization, as an aid to the excavation or for the dissemination of works (for example, in a museum) [11] and [12]. The information obtained by CT scan is transcribed in a visual manner and its inherent detail can be used much more widely in the domain of the latest $3 \mathrm{D}$ technologies, such as virtual reality, augmented reality, multimodal interactions and additive manufacturing. In combining these medical imaging techniques, it becomes possible to identify and scientifically analyze non-visible objects by efficient and non-destructive methods, to assess their fragility and their state of preservation. It is also possible to assess the restoration of a corroded artifact [9], to visualize, to analyze and to physically manipulate an inaccessible or fragile object (CT, 3D printing) and to observe the context of our hidden archaeological heritage (virtual reality, augmented reality or mixed, 3D). The development of digital technologies will hopefully lead to a democratization of this type of analysis.

The work presented in this paper aims to develop a nondestructive workflow for analyzing and documenting the internal structure of artifacts, improving diagnostic techniques and knowledge by combining medical imaging technologies such as Computed Tomography (CT) with 3D printing. Our methodology allows the creation of digital and physical 3D surrogates of objects to investigate, analyze and interpret their internal structure through volumetric scanning, $3 \mathrm{D}$ image rendering and 3D printing. This work is developed in the context of the project $X$ presented in next section.

Combinations of CT scans and 3D printing technologies have already been proposed in $\mathrm{CH}$ contexts. The projects presented in [1] and [2] both propose the use of 3D printers, combined with CT images, to reproduce high-value pieces, Chinese chess pieces in the first case, and gold jewelry in the second case. In [10], copies of fragile bones are used for sharing during the study process and for exhibition.

This methodology was also successfully applied to physically access encased artifacts through 3D images and to create $3 \mathrm{D}$ printed replications without any irreversible physical damage to the original material [3], even in the case of a disaggregated artifact [4]. In particular, in the first work, a removable copy of a Gallic weight illustrates how this technique allowed for a better understanding of the internal 
structure of an artifact. This is also the case in the work of McKnight and colleagues [5], where a bone assembly from an animal mummy has been reconstituted for scientific analysis and public exhibition purpose. In both [6] and [2], a $3 \mathrm{D}$ print of the original shape of the archaeological material composed of an aggregate of several objects is proposed. This kind of production is useful to study the shape of the disaggregated container.

In addition to these different works, it can also be interesting to have a view of both the external and internal structure of archaeological material in order to understand its production process, or to spatially localize the different notable internal items. The goal of the work presented in this paper is to propose a tangible representation of a complex intricate structure through advanced $3 \mathrm{D}$ printing. The process is applied to a funeral urn and combines CT scans, 3D model processing and $3 \mathrm{D}$ printing.

We illustrate our approach using the study of several artifacts from the recent excavation of the Warcq chariot burial (Ardennes, France). We present how different imaging and 3D technologies were integrated into the archaeological and curation process whilst comparing it to existing methods. In particular, our process is based on CT scans, photogrammetry and complex $3 \mathrm{D}$ printing. We highlight its relevance, and future research perspectives will also be discussed, in particular, within the context of preventive archaeology.

\section{CONTEXT}

\section{A. The project INTROSPECT}

The project INTROSPECT is an international project that aims to develop, for archaeologists, new uses and tools that facilitate access to new knowledge through interactive numerical introspection methods that combine computed tomography with $3 \mathrm{D}$ visualization technologies, such as virtual reality, tangible interactions and $3 \mathrm{D}$ printing. It is a research collaboration between researchers in computer science, archeology and museums. The scientific heart of the project is the systematization of the relationship between the artifact, the archaeological context, the digital object and the virtual reconstruction of the archaeological context that represents it and its tangible double resulting from the 3D impression. This axiomatization of its innovative methods makes it possible to enhance our research on our heritage and to make use of accessible digital means of dissemination. This approach breaks with traditional methods and can be applied to specific archaeological problems: various case studies are examined in various archaeological contexts.

\section{B. Archaeological context}

In the context of a preventive archaeological investigation of the route of the A304 motorway being constructed by the Dreal between Charleville-Mézières and Rocroi, an exceptional aristocratic Gallic grave at Warcq (Fig. 1) was discovered by Inrap and excavated by a combined team composed of archaeologists from the Ardennes departmental archaeology unit and from Inrap [7]. This type of aristocratic grave, containing a ceremonial chariot, emerges in the 7th century B.C. and disappears with the end of the Gallic period. Champagne-Ardenne is famous for such funerary practices, which are generally dated to the start of the second Iron Age $\left(5^{\text {th }}-4^{\text {th }}\right.$ century B.C.). The remains discovered in the Warcq grave have now been revealed to be exceptional. The vast funerary chamber $(5.50$ $\mathrm{x} 2.80 \mathrm{~m}$ ) was preserved to a depth of more than a meter. In this damp environment, the wooden walls and ceiling were extremely well preserved. Over time, the latter had collapsed directly onto the floor of the chamber, covering the deceased and his goods. The funerary artifacts discovered were of unusually high quality. The main item was a two-wheeled ceremonial chariot (Fig. 2). The vehicle was carefully decorated, particularly with pieces of bronze, in places set with dark blue or yellow glass paste on the chariot body and hubs. Other, more mysterious, wooden objects were also covered in fine gold leaf.

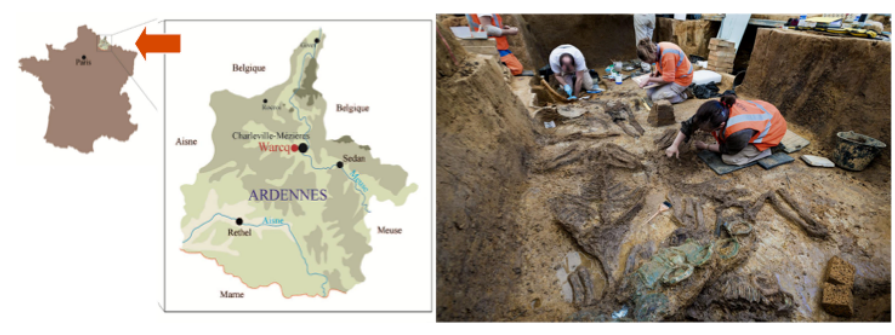

Figure 1: Localization of the grave in North-East of France.

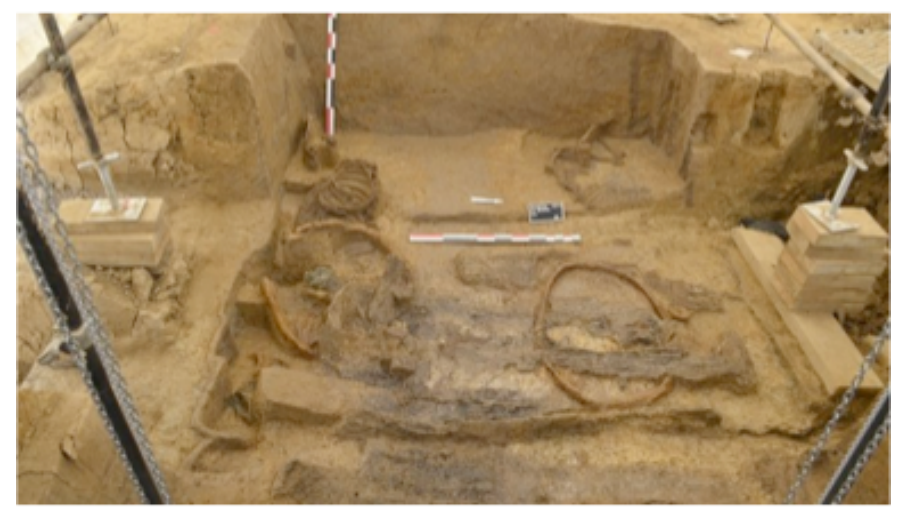

Figure 2: The two-wheeled wagon deposited in the burial chamber (C) E. Millet)

One of the most spectacular elements was the burial of four horses: two in the southwest and northwest corners, and two in front of the chariot, beneath the yolk. The deceased person, most likely a man, was lying on the body of the chariot (Fig. 3).

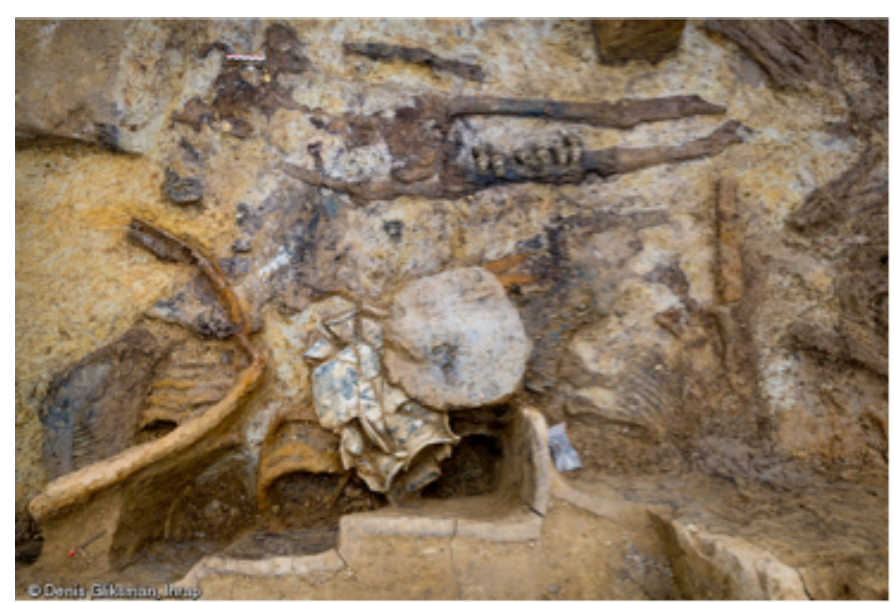

Figure 3: The deceased person and the deposit of ceramics (C) D. Glicksmann)

An unusual collar, in resin and wax covered with gold leaf, was still around his neck. A fibula was inserted into his 
garments. A dagger, a pair of shears and an iron razor were lying alongside him.

Five pottery vases had been crushed when the chamber ceiling collapsed. Lastly, a pig constituted one of the food offerings.

Everything here indicates that this was an extremely elaborate, very spectacular funeral, some aspects of which are very uncommon in chariot graves in Champagne. These include the presence of four horses and also the gold-leafcovered ceremonial chariot.

One of the vases discovered, which has a baluster shape, bore a geometrical decoration created with tin. Before archaeologists have even begun to define the exact chronology, a number of indicators enable the Warcq chariot grave to be attributed to the middle of the 2nd century B.C. (La Tène C2/D1), a period in which this method of inhumation had all but disappeared.

\section{MEthodology OF THE STUdy}

The study was performed following a global process developed in the project INTROSPECT in order to combine different digital technologies with existing archaeological and restoration processes.

\section{A. General process}

This process presented in Fig. 4 is centered on the archaeological material that can be an artifact as well as a sample from an excavation or an aggregate of objects. After the removal of deposition and consolidation, the material is transmitted to the imaging laboratory to be explored by the CT scan, or digitized by photogrammetry, laser scan or other digitization techniques.

The data collected during this step, consisting of DICOM raw-data in the case of a CT scan, allow several possible exports through post-processing: analysis, 3D volume rendering and mesh generation for $3 \mathrm{D}$ printing. The interest of CT scan is that it gives information on the internal structure of the archaeological material. CT scans, or tomo-densitometry, allow cut-away views of an object (tomo) and analysis of its composition (densito). The slices, which are 2D images, can be stacked to reconstitute the volume of the object. It can then be digitally seen from all angles, virtually sliced with respect to different axes, or segmented according to specific focuses.

Volume rendering and $3 \mathrm{D}$ copies of the material provide relevant information to help further physical excavation and the restoration process.

The 3D data produced at this step can be used for virtual reality, augmented reality or mixed reality applications development, or for 3D printing, with an objective of evaluation and use by experts of Cultural Heritage.

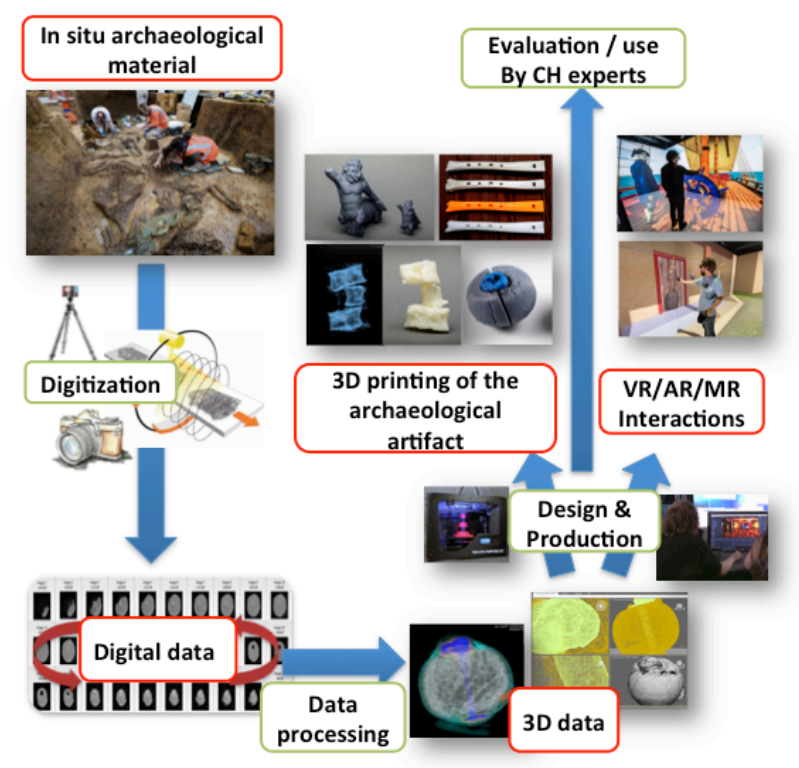

Figure 4: Global process of the study.

As the ground environment of the excavation in Warcq was very wet, it was decided to sample complete blocks in the grave around some pieces of interest that required a cautious excavation process. Seven blocks were scanned in order to prepare their micro-excavation and restoration. The block S1 contains the wheel hub, the blocks S2 and S3 contain two buckets, the block S4 contains the rim of one wheel, the blocks S5 and S6 contain the harnessed heads of the two horses ahead the chariot (Fig. 5) and the block S7 contains a yoke.

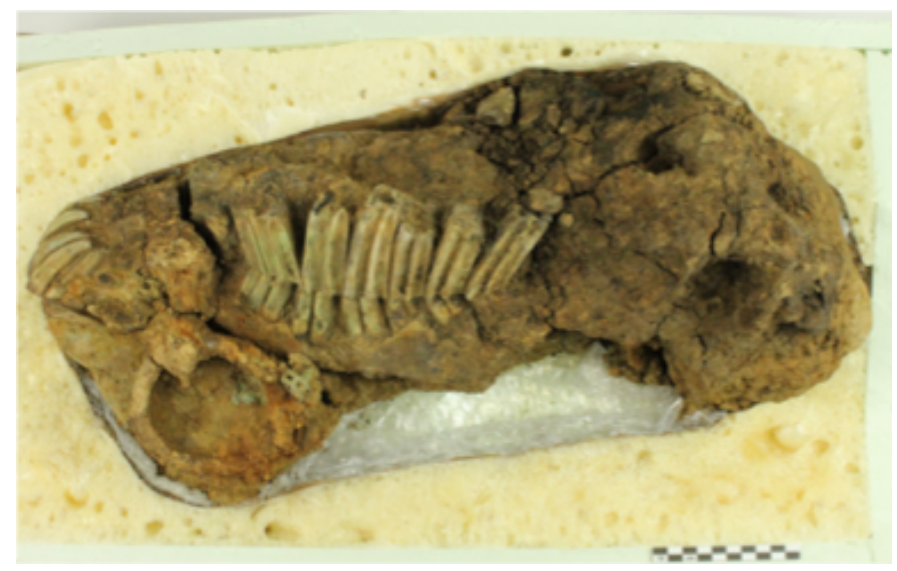

Figure 5: The block S5 with one harnessed head.

\section{B. Technical environment}

The CT scanner used in this study is a Siemens SOMATOM sensation 16 (Fig. 6), owned by a French private company who delivers services and expertise on $\mathrm{X}$ Ray images and associated tools.

The three-dimensional explorations were performed through two passes (acquisition) and 2D/3D images postprocessing. The two acquisitions were a topogram (or radio mode), for positioning the slices to be realized, and a helix scan.

The scan generates a dataset under DICOM format [8] of $512 \times 512$ pixels $2 \mathrm{D}$ slice images. The seven blocks were scanned with the acquisition parameters listed in Table 1. 
The nominal single collimation width was set to $0.75 \mathrm{~mm}$, with a thickness of the cuts in the image series of $1 \mathrm{~mm}$. The blocks were composed mainly of sediments, bones fragments, metal parts and wood, so we used and extended the Hounsfield scale for densities.

TABLE I. CT SCAN ACQUISITION PARAMETERS

\begin{tabular}{|l|c|c|c|c|c|c|c|}
\hline \multirow{2}{*}{} & \multicolumn{7}{|c|}{ Samples } \\
\cline { 2 - 8 } & $\boldsymbol{S 1}$ & $\boldsymbol{S 2}$ & $\boldsymbol{S 3}$ & $\boldsymbol{S 4}$ & $\boldsymbol{S 5}$ & $\boldsymbol{S 6}$ & $\boldsymbol{S 7}$ \\
\hline $\begin{array}{l}\text { Scan } \\
\text { Length } \\
\text { (mm) }\end{array}$ & 302 & 259 & 370 & 562.5 & 636 & 498 & 637 \\
\hline $\mathbf{k V}$ & 140 & 140 & 140 & 140 & 140 & 140 & 140 \\
\hline mAs & 175 & 250 & 250 & 228 & 214 & 214 & 220 \\
\hline $\begin{array}{l}\text { Nb of } \\
\text { slices }\end{array}$ & 411 & 349 & 508 & 787 & 893 & 696 & 894 \\
\hline
\end{tabular}

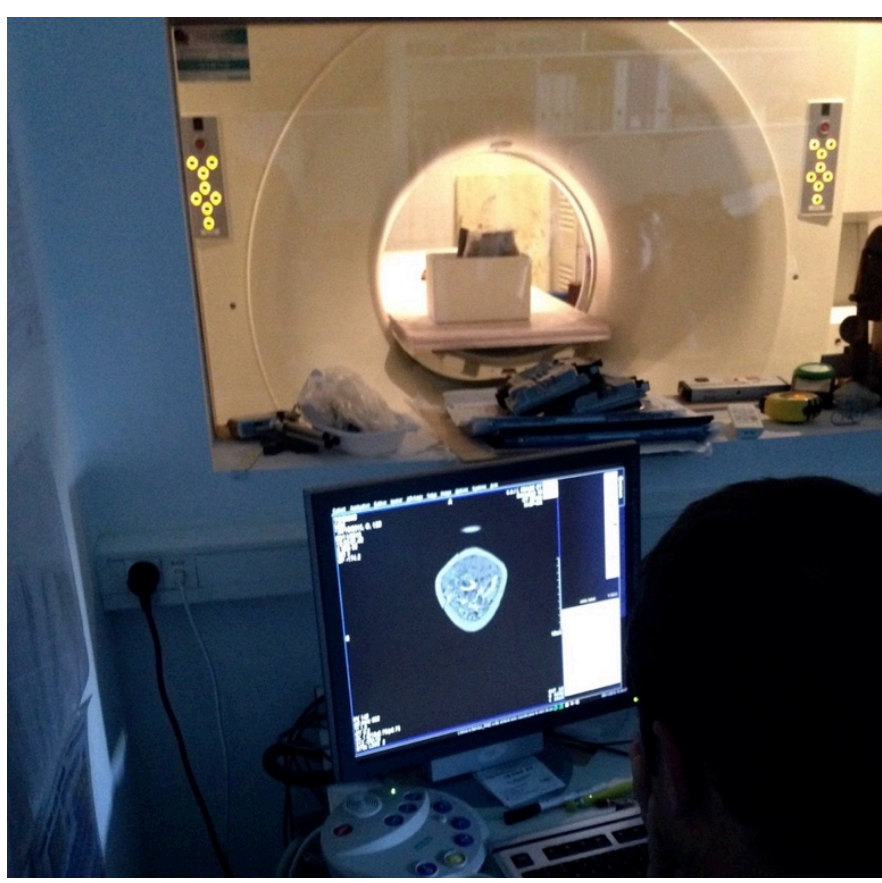

Figure 6. CT scan of one block

The data generated during the CT scan was processed with the open source software Horos, https://horosproject.org/, an image processing application for Mac dedicated to DICOM images in order to perform preliminary studies and segmentation and generate volume rendering (Fig. 7) and surface rendering.

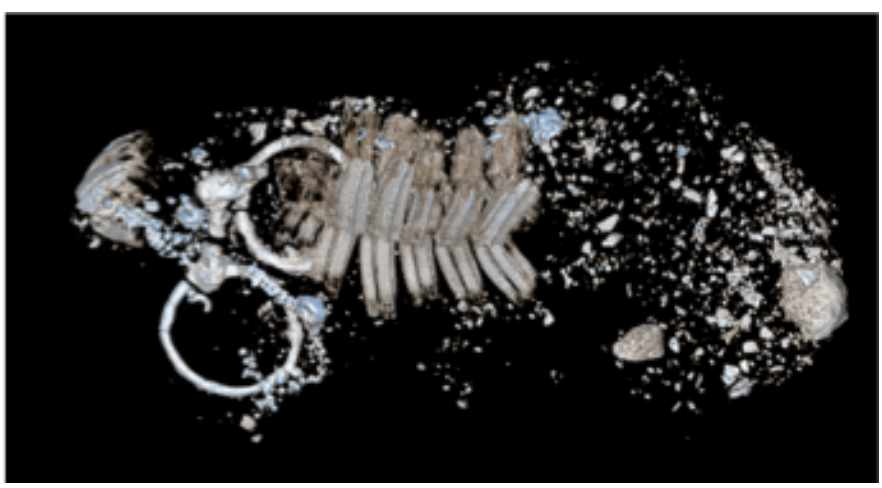

Figure 7. Volume rendering of the block S5

\section{Micro-excavation process}

CT scan data (sections, 3D reconstruction) guided all stages of micro-excavation (Fig. 8). These operations were carried out in collaboration between the archaeologist and the curator. The whole process of micro digging has also been documented using photogrammetry. All the objects taken in bulk followed the same process: the micro-search, guided by $\mathrm{CT}$ and X-ray, under a magnifying glass, is followed by a cleaning for the study by micro-sandblasting under a binocular loupe (Fig.9).

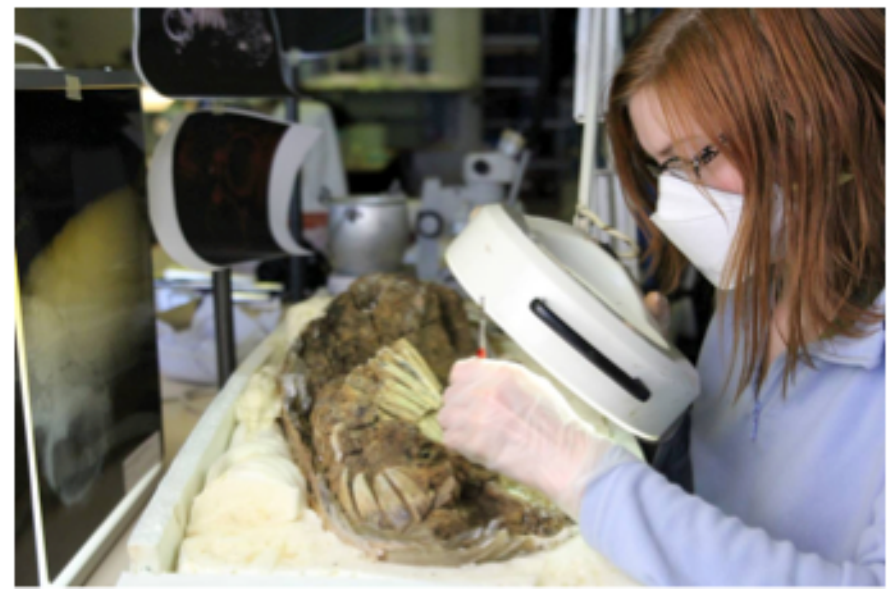

Figure 8. Micro search, guided by CT scans and x-rays, of one of the horses' heads under magnification loupe (C R. Bernadet)

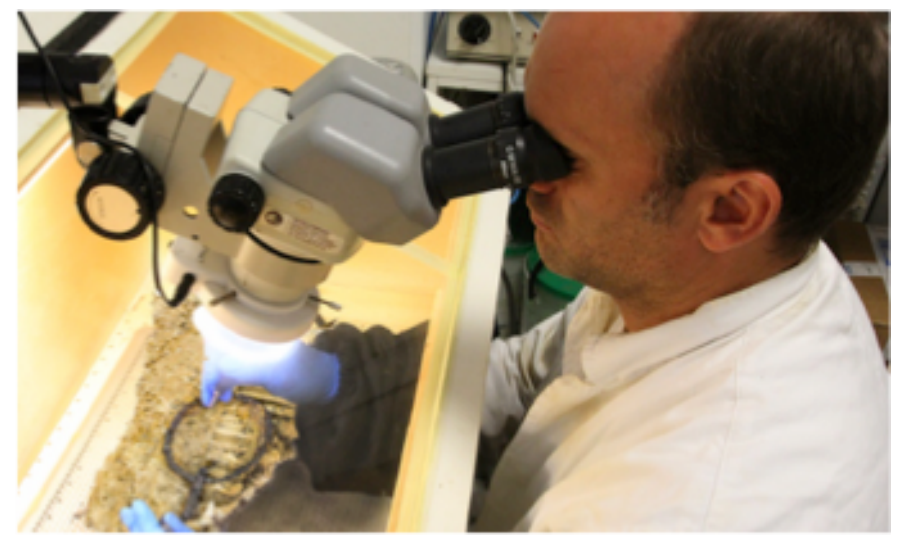

Figure 9. Cleaning for study of the horse bit by micro-sandblasting under a binocular loupe (@ R. Bernadet)

Figure 10 presents the horse's head, once consolidated, with the bit cleaned of the superficial corrosion layer, and Fig. 11 presents the bit once cleaned for study and taken from the horse's skull, with the detail of the ring, on which are visible mineralized organic remains and cuprous alloy cabochons that covered the nails that decorated the harness. 


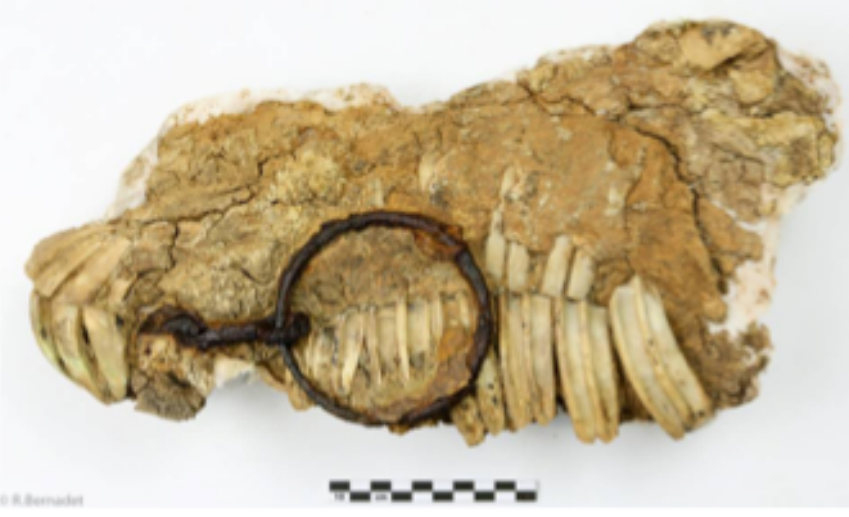

Figure 10. Consolidated head (block S6) after cleaning (C R. Bernadet)
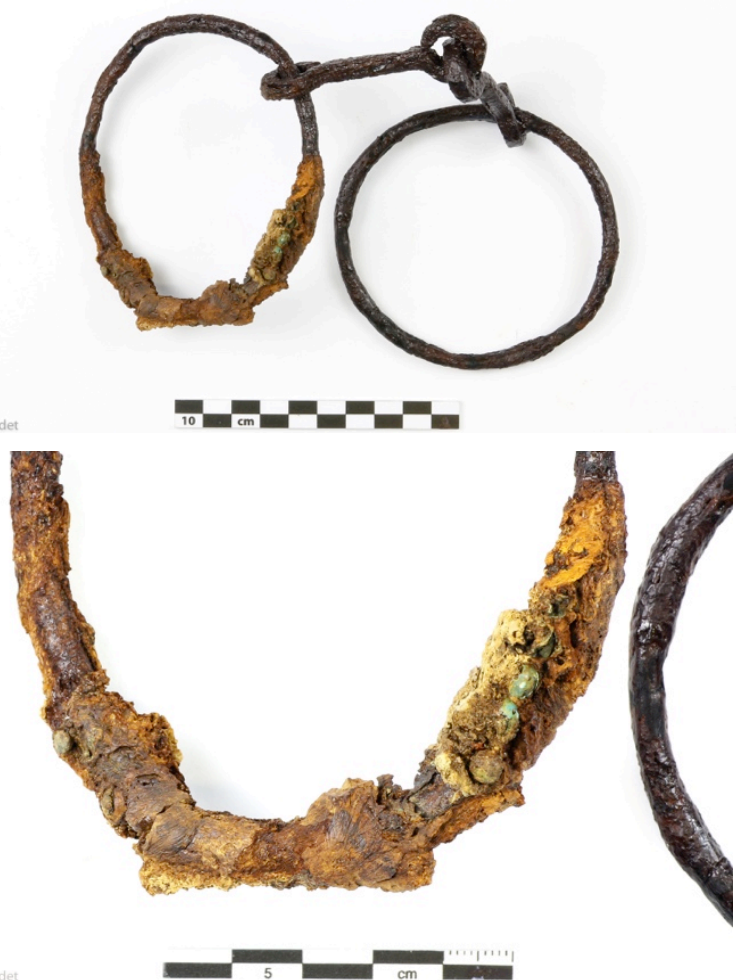

Figure 11. Bit from the second head (block S6) after extraction (C) R Bernadet)

This process has been particularly efficient for the study of two harnessed horse heads, for example, where it has allowed the researchers to to observe, quantify and locate the presence of objects inside the samples upstream of the intervention, despite the poor state of conservation. The information collected was very useful to assist the restorer during delicate operations of micro-excavation, including locating the original surface of the objects during the cleaning for study, while allowing a long-term backup of the context. The most important example is the decoration of the harness. These visible elements on the images from the CT scan are very small (Fig. 12). The elements were composed of very thin sheet (less than $1 \mathrm{~mm}$ ) of copper alloy originally covering the nail heads. They were not all found during the micro digging because of their size, the very complex sediment to search through and their state of conservation. The iron nails are not preserved. They are not lost because the sieving of the sediment will help to find them. Imaging and direct observations on the micro frame, however, will make it possible to restore the harness, the position of the belt loops and the identifiable straps thanks to the ornamental rivets.

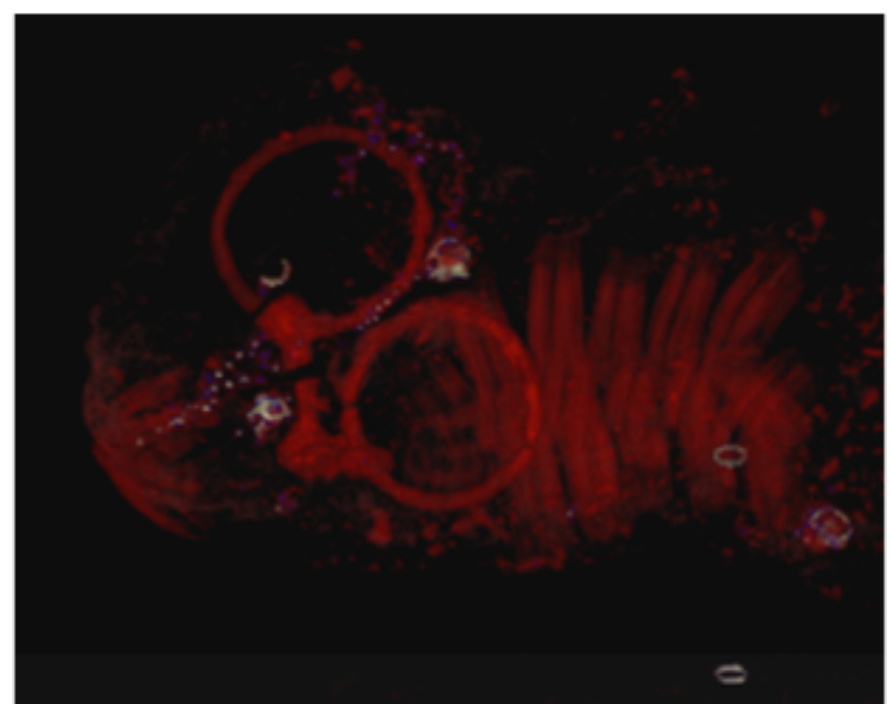

Figure 12. Small nails highlighted in volume rendering of head number 1 (block.S5)

\section{Data processing and $3 D$ printing}

The 3D surface rendering functionality was used to generate $3 \mathrm{D}$ meshes corresponding to different density ranges. This functionality allows for the generation of the surface of a set of points whose density value is within a defined range.

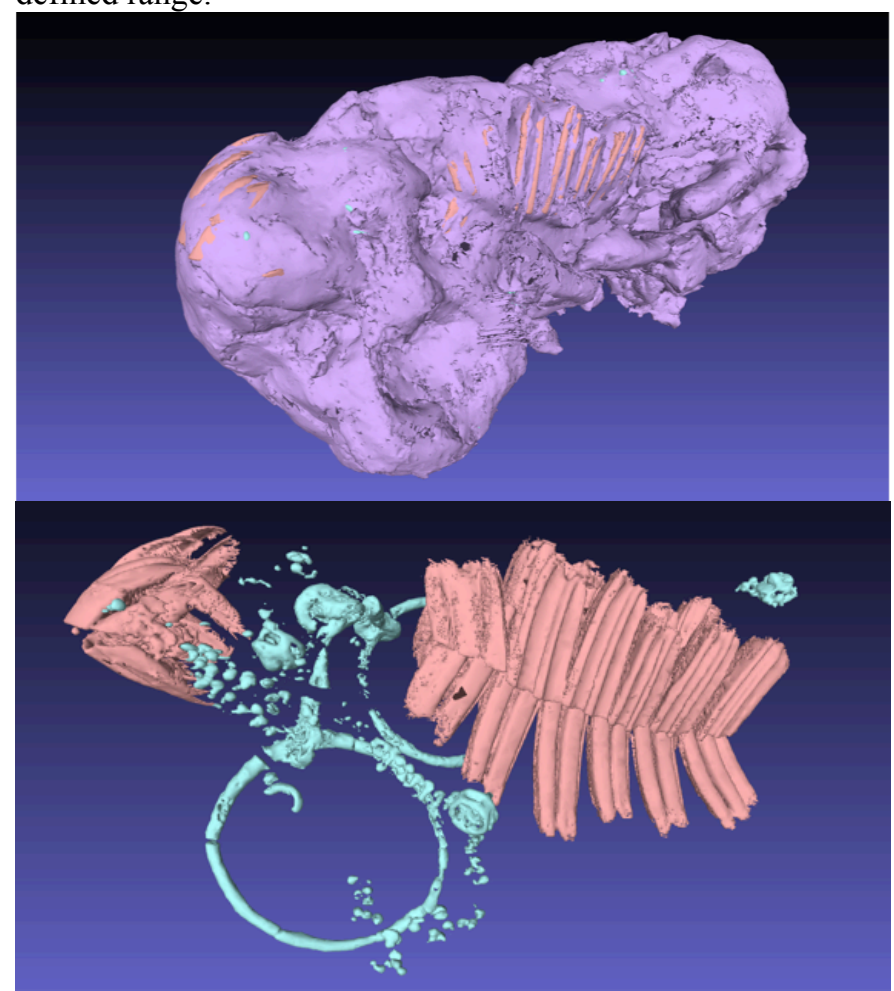

Figure 13. Top: The whole model with the block shape. Bottom: meshes of teeth (in red) and metal parts (in blue).

The 3D model was then manually processed in order to remove unwanted data and automatically processed to get a ready-to-print file.

The goal of this part of the work was to produce a $3 \mathrm{D}$ print that highlights the spatial organization of the metal 
parts of the harness. We chose to use a technique of transparent printing of the block, with different colors for the internal elements.

Three meshes were generated from the Dicom data, one for the whole block, one for the teeth (density greater than 1300 ) and one for the metal parts (density greater than 4000) (Fig. 13). As the external shape of the block was very jagged, we generated a convex hull around the teeth and metal part to constitute the transparent support of our 3D printing (Fig. 14).

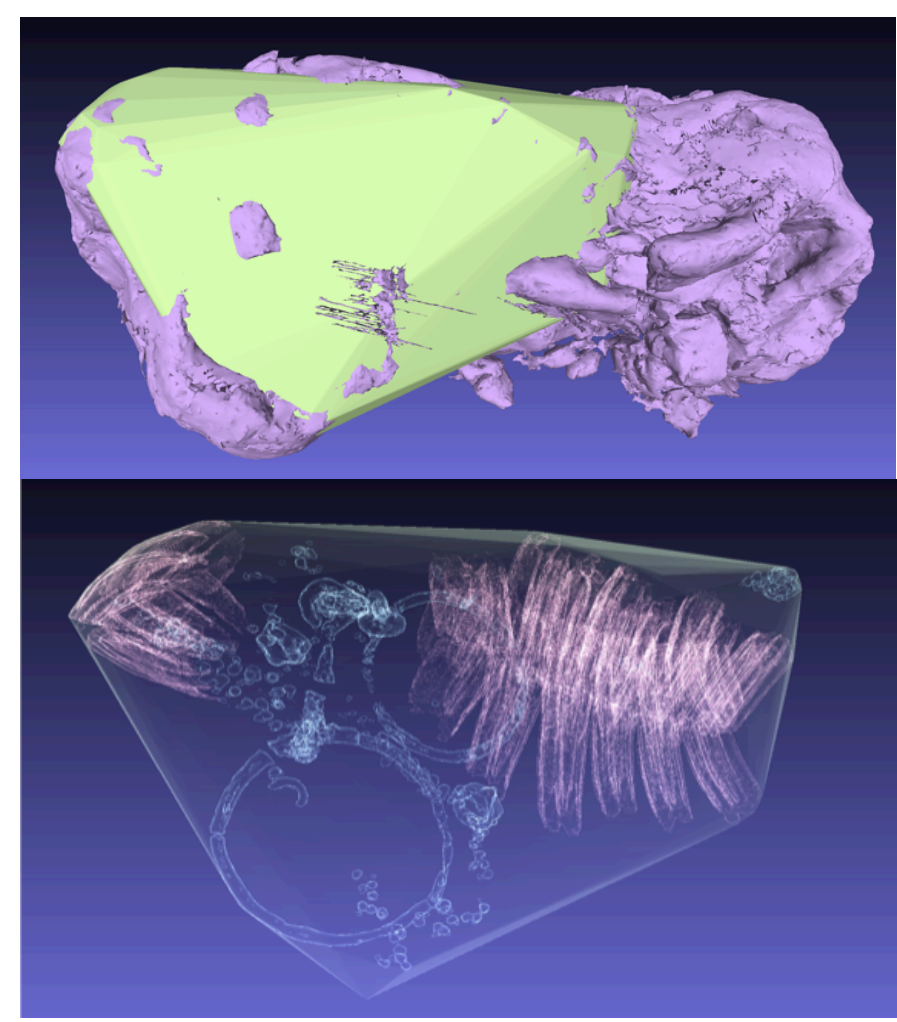

Figure 14. Top: The convex hull inside the block. Bottom: view of the internal elements inside the hull.

The transparent 3D printing was performed by a private company, with a technology of multi-material and multicolor additive manufacturing by resin polymerization, on a Stratasys Objet500 Connex3 3D printer. This printer has a printing capacity of $49 \mathrm{~cm} \times 35 \mathrm{~cm} \times 25 \mathrm{~cm}$, with an accuracy of $30 \mu$.

The object was printed at 1:2 and 1:4 scale with successive layers, from the bottom up, using transparent resin for the hull, red matter for the teeth and blue matter for the metal parts (Fig.15, top). The resulting printed object was covered with a pink support matter (Fig. 15, bottom). An important post-processing of the object produced by the $3 \mathrm{D}$ printer is required to obtain a good transparency rendering (Fig.16). This post processing, which lasted one week, consisted of four phases: (i) removal of the support matter; (ii) photo-bleaching for $72 \mathrm{~h}$ at 6500 kelvins ( $«$ day light »); (iii) sanding cycles with different sized grit (from 180 to 800 ); and (iv) coating in sterile conditions. In the resulting 3D-printed object, the internal parts are completely visible thanks to the hull shape.

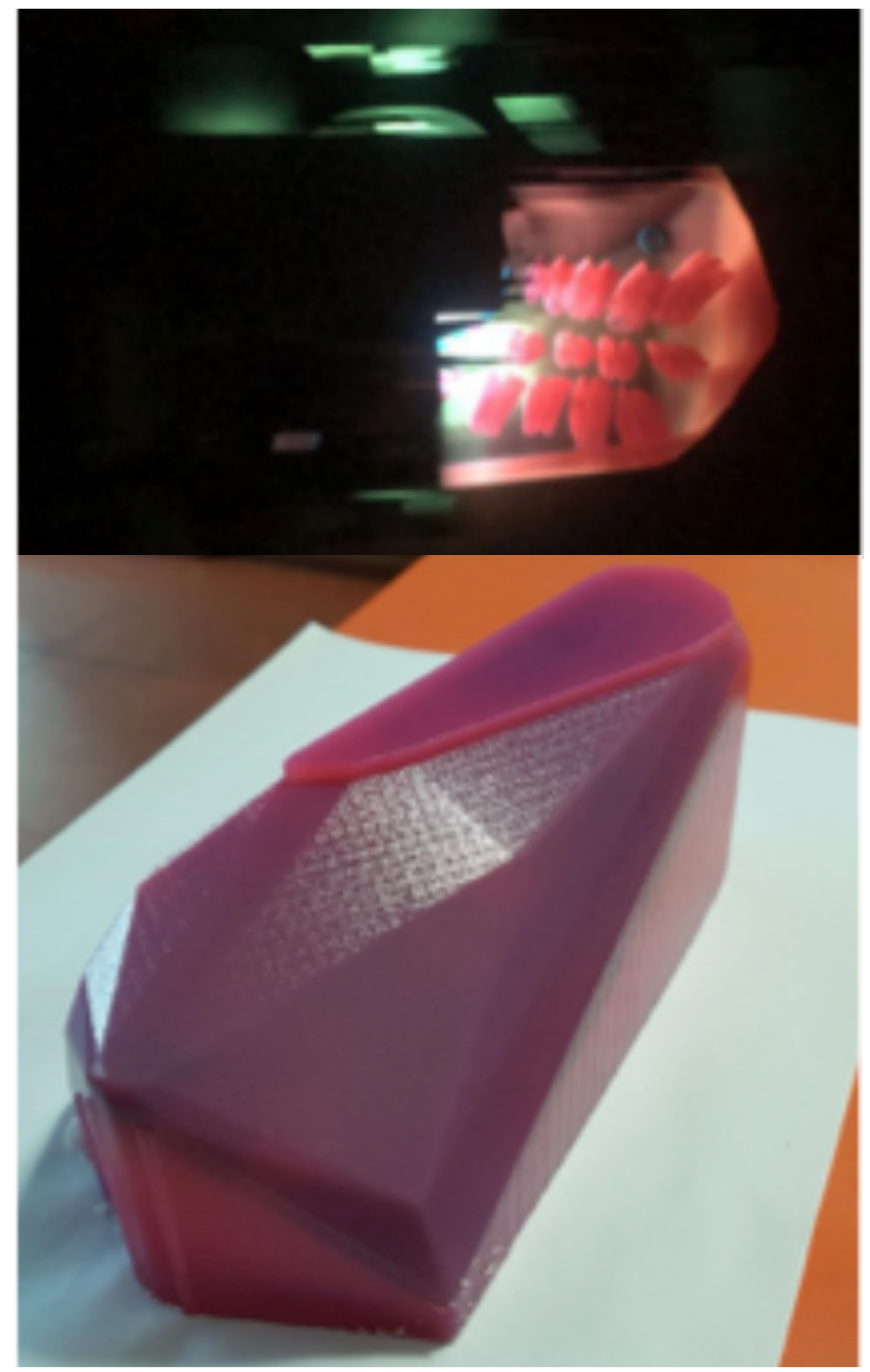

Figure 15. Top: top view of the ongoing printing process. Bottom: The 3Dprinted objet with its support matter.

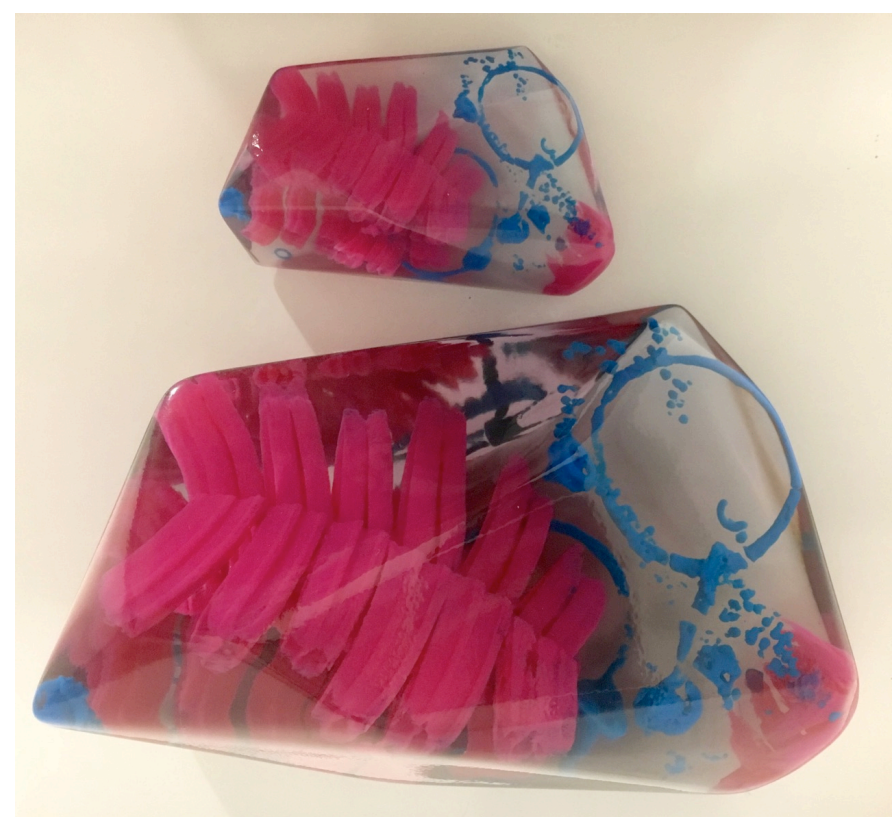

Figure 16. 3D printings at 1:2 and 1:4 


\section{DISCUSSION}

The complexity and the exceptionality of the funerary furniture, found in Warcq's chariot tomb (horse heads still harnessed, yoke, elements of the gilded tank body, etc.) and, on the other hand, its deplorable state of conservation fully justified the implementation of in-situ bulk sampling of some of these objects and the use of computed tomography as a non-destructive analysis technique. This process made it possible to quickly acquire samples, some of which were large.

Computed tomography is a definite asset in microexcavation interventions of bulk samples consisting of composite objects (metals, organic) and multi-material assemblies (skulls still harnessed). It allows researchers instantaneously to observe and quantify the presence of objects within the samples, to determine their location, their nature, their association and, as far as possible, to help identify them.

In the second step, CT images will guide the restorer's hand during the very delicate operations of microexcavation and inform the location of the original surface during the cleaning for study. It also represents a primordial documentation, by its three-dimensional character, by allowing the registration of the position of the different elements, one respectively to the others, before the disassembly of the samples in blocks [9]. For the same reasons, we also set up a photogrammetric record of the different blocks cleaned before any disassembly, when it was made necessary for the study (removal of the teeth of the skulls of horses for the archaeozoological study).

The limits of this imaging technique are mainly related to the differentiation of materials when their density is similar: an object or part of an iron object that is extremely degraded will not be differentiated, for example, from highly mineralized organic elements. In addition, the observation of a tomodensitometric image requires a good awareness of the operator to these issues and a very good knowledge of the furniture from the archaeologist and the restorer, because even if the archaeological information is there, it is not always obviously identifiable and understandable. The cleaning intervention for study therefore remains fundamental for the understanding of archaeological furniture.

In the context of our study, computed tomography was an essential basis for the development of a return of the harness, the position of the belt loops and the identifiable straps thanks to the ornamental rivets. The transparent $3 \mathrm{D}$ printing constitutes a tangible spatial recording of the horse head, with the nails visible; it offers a better visualization and perception of the volume of spatialization and of the relation between the objects. The head itself was not restorable aside from the teeth, as there is no more bone matter. 3D printing has thus a long-term goal of safeguarding

Tomography and 3D printing are study mediums and a long-term safeguard against physical interventions that are, by nature, destructive. It remains necessary to incorporate the variety of skills that exist (conservators, metal specialists, etc.).

For computed tomography acquisition, the quality of the image depends on the device and its intrinsic performance, as well as on the choices of the person who makes the images. Indeed, if a large number of complex operations are automated, there are still technical choices to be made concerning the field and the cutting thicknesses, depending on the nature or size of the object and the research problem and technical choices that must also take into account the scientific issues of the archaeologist.

Computed tomography and $3 \mathrm{D}$ printing are tools within an "operating chain" of analysis that involves the interaction of different trades. However, these technologies offer new perspectives of operational approaches to archaeological bulk samples, even of large size, as well as opening new fields of investigation.

\section{CONCLUSION AND PERSPECTIVES}

The use of non-invasive means of investigation with high technological complexity for the analysis of archaeological material is currently limited, reserved most often for exceptional discoveries. The democratization of these tools and their controlled cost show that on the contrary, that these methods and the results of their use for the study of the materials resulting from preventive archeology becomes possible in a larger number of cases, in order to refine the reading of complex, composite and/or altered objects.

Numerical data from computed tomography also makes it possible to design visualization and interaction modalities that open fields of study that are still underexplored. It is also possible to complete visual analysis using computational software, such as Matlab, in order to carry out qualitative and quantitative analysis.

The work presented here illustrates the usefulness of the link between images obtained from CT scan and 3D data usable in additive manufacturing. This $3 \mathrm{D}$ data can also be exploited in other 3D interactive technologies like virtual reality and augmented reality that could also be integrated in the "operating chains" of archaeologists and curators.

\section{ACKNOWLEDGMENT}

The authors whish to thank the company CAD'indus for the work on $3 \mathrm{D}$ printing.

\section{REFERENCES}

[1] S. D. Laycock, G. D. Bell, N. Corps, D. B. Mortimore, G. Cox, S. May, and I. Finkel. 2015. Using a Combination of Micro--Computed Tomography, CAD and 3D Printing Techniques to Reconstruct Incomplete 19th-Century Cantonese Chess Pieces. J. Comput. Cult. Herit. 7, 4, Article 25 (February 2015)

[2] H. Haßmann, T. Heintges, B. Rasink, S. Winghart,F.-W. Wulf, Der bronzezeitliche Hortfund von Gessel, Stadt Syke, Landkreis Diepholz, Berichte zur Denkmalpflege in Niedersachsen Veröffentlichung des Niedersächsischen Landesamtes für Denkmalpflege Hameln Niemeyer, Vol. 32, No. 1, 2012, p. 23-28

[3] Nicolas T., Gaugne R., Tavernier C., Gouranton V., Arnaldi B. Preservative Approach to Study Encased Archaeological Artefacts. Int. Conf. on Culturage Heritage, LNCS, Vol.8740. pp.332 - 341, 2014.

[4] Nicolas T., Gaugne R., Tavernier C., Petit Q., Gouranton V., Arnaldi B., Touching and interacting with inaccessible cultural heritage, in Presence: Teleoperators and Virtual Environments, MIT Press, 2015, 24 (3).

[5] L.M. McKnight, J.E. Adams, A. Chamberlain, S.D. AthertonWoolham, R.J. Bibb, Application of clinical imaging and 3D printing to the identification of anomalies in an ancient Egyptian animal 
mummy. J. of Archaeological Science: Reports, 3, 2015,pp. 328 332.

[6] T. Nicolas, R. Gaugne, C. Tavernier, V. Gouranton, B. Arnaldi, « Tomography and 3D printing for the study of archaeological artefacts » in proceedings of the conference " New technologies for cultural heritage », Cambridge Scholars Publishing, to appear.

[7] Millet, E., Roseau, B., LA tombe à char de Warcq : rapport de fouilles, Cesson-Sévigné : Inrap, to appear.

[8] Mustra, M., Delac, K., Grgic, M.: Overview of the DICOM Standard. ELMAR. 50th International Symposium. pp. 39-44, 2008.

[9] M. Biron, S. Hurtin, T. Nicolas, C. Tavernier, La tomographie des objets archéologiques complexes et /ou altérés : outil d'identification, d'analyse et d'aide à la décision pour les mesures conservatoires, In Restaurer l'ordinaire. Exposer l'extraordinaire, Journée des Restaurateurs en Archéologie (JRA), Arles 2014
[10] V. Mitsopoulou, D. Michailidis, E. Theodorou, S. Isidorou, S. Roussiakis, T. Vasilopoulos, S. Polydoras, G. Kaisarlis, V. Spitas, E. Stathopoulou, C. Provatidis, G.Theodorou, Digitizing, modelling and 3D printing of skeletal digital models of Palaeoloxodon tiliensis (Tilos, Dodecanese, Greece), Quaternary International 379, 2015

[11] Re A., Corsi J., Demmelbauer M., Martini M., Mila G., Ricci C. 2015. "X-ray tomography of a soil block: a useful tool for the restoration of archaeological finds ", in: Heritage Science, 3:4, Science Letters, 246 : 102-108.

[12] Jörg Stelzner, Nicole Ebinger-Rist, Christina Peek \& Burkhard Schillinger (2013) The application of 3D computed tomography with $\mathrm{X}$-rays and neutrons to visualize archaeological objects in blocks of soil, Studies in Conservation, DOI: 10.1179/sic.2010.55.2.95 